\title{
A general practice based survey of bronchial hyperresponsiveness and its relation to symptoms, sex, age, atopy, and smoking
}

\author{
C J Trigg, J B Bennett, M Tooley, B Sibbald, M F D'Souza, R J Davies
}

Academic

Department of Respiratory Medicine, St Bartholomew's Hospital, London

C J Trigg

J B Bennett

R J Davies

Canbury Medical

Centre, Kingston,

Surrey

M Tooley

B Sibbald

M F D D'Souza

Address for reprint requests:

Dr R J Davies, Academic

Medicine, St Bartholomew's

Hospital, London EC1A

7BE.

Accepted 14 August 1990
Abstract

The prevalence and associations of bronchial hyperresponsiveness were investigated in a general practice population. The sample was obtained by using every 12th patient on the practice age-sex register, replacing non-responders with corresponding age and sex matched individuals from up to two further 1 in 12 samples. The response rate was $43 \%$; 366 patients were studied. Doubling concentrations of methacholine were given to a maximum of $32 \mathrm{mg} / \mathrm{ml}$ or until a $20 \%$ fall in forced expiratory volume in one second $\left(F E V_{1}\right)$ occurred (provocation concentration, $\mathrm{PC}_{20} \mathrm{FEV}_{1}$ ). Bronchial hyperresponsiveness was defined arbitrarily as a $\mathbf{P C}_{20} \mathrm{FEV}_{1}$ of $2 \mathrm{mg} / \mathrm{ml}$ or less (or $11 \mu \mathrm{mol}$ cumulative dose, $\mathrm{PD}_{20} \mathrm{FEV}_{1}$ ). The prevalence of bronchial hyperresponsiveness was $23 \%$. Bronchial hyperresponsiveness was not associated with age but was more prevalent in women than men (31\%: $13 \%)$. It was also more common in those who had ever wheezed $(39 \%)$ and in those who had had an attack of rhinitis in the preceding month $(45 \%, p<0.1)$, in atopic individuals (30\%), and in smokers $(32 \%)$, but it was not associated with cough or dyspnoea. There was a positive correlation between $\mathrm{PC}_{20} \mathrm{FEV}_{1}$ and resting $\mathrm{FEV}_{1}$ $(r=0.288)$ and a negative correlation between $\mathbf{P C}_{20} \mathrm{FEV}_{1}$ and mean daily peak flow variability $(r=-0.356)$. Stepwise binary logistic regression analysis showed significant independent effects on $\mathrm{PC}_{20} \mathrm{FEV}_{1}$ for mean daily peak flow variability, gender, number of positive skin test responses, resting $F E V_{1}$, and mean histamine skin weal area, but no relation with smoking or mean allergen weal area. The prevalence of bronchial hyperresponsiveness was much higher than the prevalence of diagnosed asthma in the practice in $1984(4.9 \%)$. Analysis of case notes of 169 individuals showed that those with bronchial hyperresponsiveness had not attended the practice more frequently for respiratory complaints during the previous five years.

The prevalence of increased bronchial responsiveness to agents such as histamine or methacholine is high in subjects with current asthma, ${ }^{12}$ and bronchial hyperresponsiveness is considered by many to be a cardinal feature of asthma. ${ }^{34}$ It is not always found, however, in current symptomatic asthma, ${ }^{5}$ and it is not specific to asthma because it has been shown to occur in chronic airflow limitation, ${ }^{6}$ rhinitis, ${ }^{3}$ and upper respiratory tract infection, ${ }^{7}$ and also in symptomless individuals with normal lung function. ${ }^{8}$

Most investigators have shown an association between bronchial hyperresponsiveness and atopy ${ }^{9-12}$ but non-atopic asthma is well recognised. ${ }^{13}$ The relation with smoking may vary with age. ${ }^{111415}$ There is a relation between airflow limitation and bronchial hyperresponsiveness, ${ }^{16}$ though lung function may be normal in hyperresponsive subjects.

Several mechanisms have been proposed to explain the presence of bronchial hyperresponsiveness, including increased bulk and contractility of bronchial smooth muscle, mediator release from damaged respiratory epithelium, ${ }^{17}$ and imbalance between nonadrenergic inhibitory and non-cholinergic excitatory fibres. ${ }^{18}$

Bronchial responsiveness to methacholine or histamine is most commonly expressed in terms of the provocation concentration $\left(\mathrm{PC}_{20}\right)$ or provocation dose $\left(\mathrm{PD}_{20}\right)$ of an agent that provokes a $20 \%$ fall in forced expiratory volume in one second $\left(\mathrm{FEV}_{1}\right){ }^{3}$ The intensity of bronchial responsiveness appears to be unimodally distributed in the population. ${ }^{19-21}$

Population studies have shown a prevalence of bronchial hyperresponsiveness that varies from $10 \cdot 3 \%$ to $24 \cdot 5 \%,{ }^{10-122122}$ far in excess of the prevalence of asthma, and especially high in children..$^{22}$ All studies show strong associations of bronchial hyperresponsiveness with atopy, smoking, and abnormal lung function. Several respiratory symptoms have also been shown to be associated, most commonly wheezing in the preceding 12 month $\mathrm{s}^{1022-25}$ but also cough, ${ }^{1021}$ dyspnoea, ${ }^{102124}$ nocturnal wheeze or dyspnoea, ${ }^{23}{ }^{24}$ and the "bronchial irritability syndrome." 25

The various surveys have used different populations and different methods for bronchial challenge. Studies in children differ from others in that age cohorts are usually studied. ${ }^{22}$ Cross sectional studies of adult populations comprise a high proportion of middle aged volunteers, non-smokers, and women. ${ }^{1124}$ The response rate is generally low for bronchial challenge testing $(36-38 \%)^{12324}$; only the Busselton study ${ }^{10}$ and the university 
based studies by Cockcroft in younger subjects $^{31219}$ have had a higher response rate. Patients participating in a general health survey ${ }^{10}$ and university students are likely to be more motivated to attend. In these studies the proportion who returned a questionnaire was given but no information on non-responders was available.

Our study aimed to determine the associations of bronchial hyperresponsiveness in a representative sample from a local population and by using a general practice population to obtain information on both responders and non-responders to determine the validity of the sample. We used methacholine as the agonist as higher doses can be given without adverse effects and a wider range of bronchial responsiveness identified in the population. ${ }^{26}$

\section{Methods}

All subjects were invited to attend the health centre, where the investigations were conducted from 1984 to 1986 . The study was approved by the ethical committee at St Bartholomew's Hospital and informed consent was obtained from each individual.

\section{MEASUREMENTS}

A respiratory and smoking history was obtained by means of a computer administered questionnaire similar to that previously described. $^{22}$

Skinprick testing was performed with six common inhalant allergens, (Bencard, Brentford-house dust $150 \%$ weight to volume (w/v), Dermatophagoides pteronyssinus $(1 \cdot 2 \%$ $\mathrm{w} / \mathrm{v}), \mathrm{B}_{2}$ grass pollen $(2 \cdot 5 \% \mathrm{w} / \mathrm{v})$, Aspergillus fumigatus $(5 \% \mathrm{w} / \mathrm{v})$, cat fur $(150 \% \mathrm{w} / \mathrm{v})$, and dog hair $(150 \% \mathrm{w} / \mathrm{v})$ in addition to histamine $(1 \mathrm{mg} / \mathrm{ml})$ and saline control solutions. A skin test response was regarded as positive if the weal was $1 \mathrm{~mm}$ greater in diameter than that of the saline control. The number of positive skin test responses and the weal area were recorded.

$\mathrm{FEV}_{1}$ was measured with a Vitalograph (Vitalograph, Maids Moreton, Buckingham) dry bellows spirometer. Inhalation tests were performed with methacholine chloride (Sigma Chemical Company Ltd, Poole). Subjects had to have an $\mathrm{FEV}_{1}$ greater than $70 \%$ of the predicted value; those who had a history of ischaemic heart disease or were pregnant were excluded.

Methacholine challenge was performed with a De Vilbiss 646 nebuliser driven by compressed air at a flow rate of 6 litres a minute. Solutions were inhaled by tidal breathing for two minutes with the nose clipped. $\mathrm{FEV}_{1}$ was measured at 30 seconds, 90 seconds, and three minutes after inhalation of each solution. FEV was $_{1}$ recorded as the best of two reproducible attempts. Subjects inhaled a control solution of phenol saline $\left(0.4 \%\right.$ phenol, $\left.0 \cdot 275 \% \mathrm{NaHCO}_{3}, 0.5 \% \mathrm{NaCl}\right)$ initially followed by increasing doubling concentrations of methacholine, from 0.06 to 32 $\mathrm{mg} / \mathrm{ml}$ for those with symptoms and from 0.25 $\mathrm{mg} / \mathrm{ml}$ to $32 \mathrm{mg} / \mathrm{ml}$ for those without symp- toms. The test was terminated when $\mathrm{FEV}_{1}$ had fallen by $20 \%$ from the lowest of the three values obtained after the control inhalation, or when the highest concentration of methacholine had been administered. $\mathrm{FEV}_{1}$ was plotted non-cumulatively against the log concentration of methacholine administered to obtain the $\mathrm{PC}_{20} \mathrm{FEV}_{1}$ by interpolation.

Subjects were asked to record their peak flow twice daily (on rising and retiring) for 14 days, using a mini-Wright peak flow meters (Clement Clarke Ltd). Daily peak flow variability was calculated as the difference between the maximum and minimum peak flow values as a percentage of the maximum value.

Retrospective analysis of the general practice notes was carried out by a single observer (C J T) for the five year period June 1982 to June 1987 without knowledge of the subject's $\mathrm{PC}_{20}$ value. Notes were analysed systematically for the number of attendances with the following complaints: upper respiratory tracttonsillitis, sinusitis, hay fever or rhinitis, "upper respiratory tract infection"; lower respiratory tract-asthma, wheeze, cough, productive cough, or bronchitis.

\section{SUBJECTS}

The study was conducted in a four partner general practice in Kingston, Surrey, with a list size of approximately 8000 patients of whom approximately 6000 were aged between 18-75 years. The practice has a particular interest in asthma and atopy and keeps detailed notes. Initially three 1 in 12 systematic samples of all patients aged 18-75 were obtained from the practice age-sex register by taking every fourth card and allocating it systematically to one of three lists. By definition, the three lists were age and sex matched to within a year in age so that non-responders from the first 1 in 12 sample could be replaced by a substitute of the same sex and similar age. We anticipated a low response rate, particularly among young working men, and thus had to approach replacements to obtain a sample that represented the demography of the practice population.

Of the 473 patients selected initially, 47 had moved from the area at the time of the study and six were judged unsuitable to participate because they had carcinoma, severe psychiatric illness, or severe cardiovascular disease. Five with severe asthma requiring regular medication with inhaled or oral corticosteroids were excluded. Thus 415 people were written to and asked if they would be willing to take part in a study of "how the lungs work." It was emphasised in the letter that people who had no evidence of respiratory illness were required as much as people who had. Those who failed to reply to the first letter were sent two further letters.

Of the 240 people (58\%) who replied, 179 ( $43 \%)$ agreed to take part in the study, though 21 of these failed to attend. Thus $158(38 \%)$ of the original sample were seen. A further 619 letters were sent to people in the replacement groups, of whom 208 took part, giving an overall sample size of 366 and an overall response rate of $35 \%$. 
Table 1 Proportion of subjects studied by age group for the range 18-75 years

\begin{tabular}{lccccccc}
\hline Age range & $18-24$ & $25-34$ & $35-44$ & $45-54$ & $55-64$ & $65-75$ & Total \\
\hline Number studied & 34 & 92 & 102 & 54 & 57 & 27 & 366 \\
Total number in practice in this age range & 754 & 1640 & 1498 & 767 & 659 & 606 & 5924 \\
$\%$ studied & 4.5 & $5 \cdot 6$ & 6.8 & $7 \cdot 0$ & 8.6 & 4.5 & $6 \cdot 2$ \\
\hline
\end{tabular}

For the retrospective analysis of attendance with respiratory complaints 169 sets of notes were analysed, stratified for the results of bronchial provocation testing: group 1: 50 sets of notes for patients with a $\mathrm{PC}_{20} \mathrm{FEV}_{1}$ of up to 2 $\mathrm{mg} / \mathrm{ml}$ (bronchial hyperresponsiveness); group 2:51 sets of notes for patients with a $\mathrm{PC}_{20} \mathrm{FEV}_{1}$ above 2 and up to $32 \mathrm{mg} / \mathrm{ml}$ ("intermediate" bronchial responsiveness); group 3: 68 sets of notes for patients with a $\mathrm{PC}_{20} \mathrm{FEV}_{1}$ above 32 $\mathrm{mg} / \mathrm{ml}$ (control group).

Notes were selected so far as possible on a 1 in 3 basis from the random list of patients studied, to avoid bias; but because more women had bronchial responsiveness we had to add men to groups 2 and 3 to maintain a constant sex ratic across the groups.

\section{STATISTICAL ANALYSIS}

The results were analysed with the $\chi^{2}$ test for the differences between proportions, Spearman rank correlation, and the BMDPLR statistical package for binary logistic regression analysis (BMDP Statistical Software Inc, Los Angeles). For the purpose of this study we took an arbitrary $P_{20} F E V_{1}$ value of $2 \mathrm{mg} / \mathrm{ml}$ or less $\left(\mathrm{PC}_{20} \mathrm{FEV}_{1} \leqslant 11 \mu \mathrm{mol}\right)$ to identify individuals with bronchial hyperresponsiveness. This is the range we have previously established in patients with asthma ${ }^{27}$ (similar to that of Cockcroft et $a l^{12}$ ). Surgery attendances with respiratory complaints were analysed after

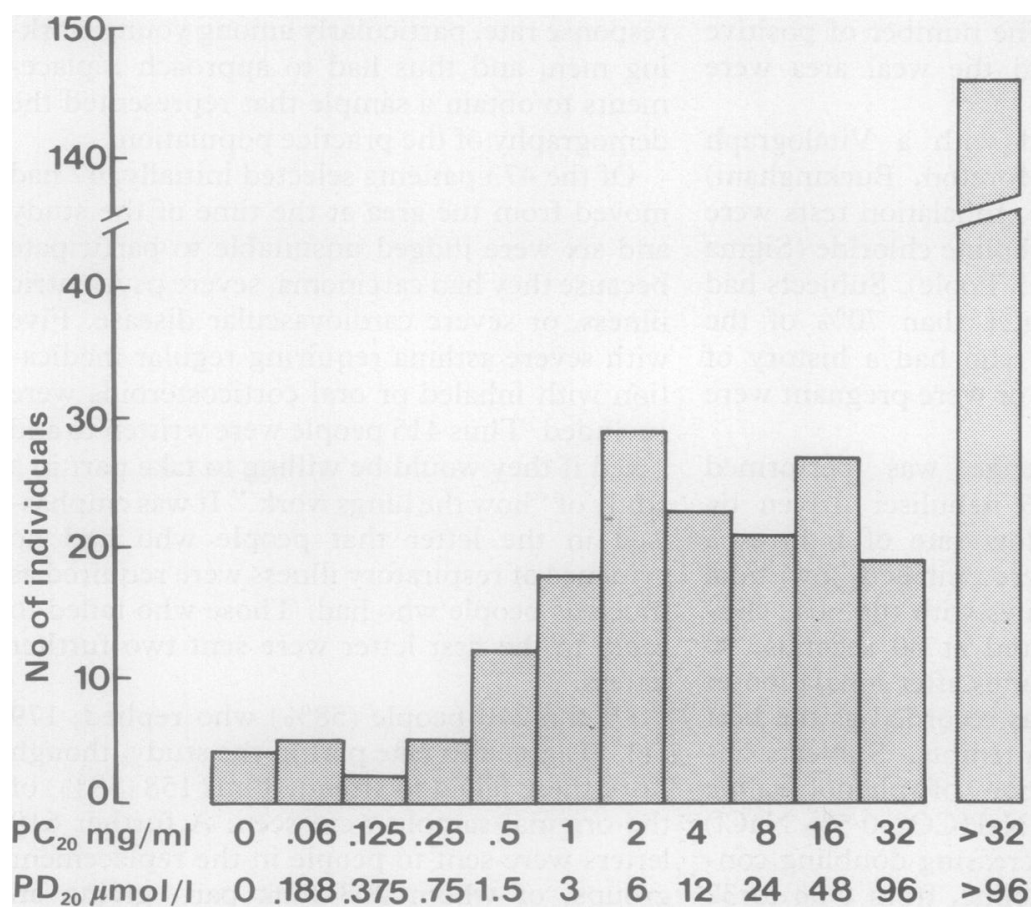

Figure 1 Distribution of bronchial responsiveness. To obtain a $P D_{20}$ value multiply $P C_{20}$ values by 3 . logarithmic transformation by analysis of variance for "upper" and "lower" respiratory tract complaints separately and in combination.

\section{Results}

The 366 subjects studied (158 men, 208 women) had an age range of 18-75 (mean 42) years. The age distribution of the sample is shown in table 1 . There was a bias towards greater recruitment in the $40-60$ year age group as we could not recruit matched replacements for 49 index individuals. The ratio of men to women reflected that in the whole practice (2650:3274 in 1984).

Methacholine challenge was carried out on 318 subjects. It was not performed in 48 subjects because of poor lung function ( $\mathrm{n}=$ $11)$, ischaemic heart disease $(n=6)$, other cardiac disease $(n=2)$, pregnancy $(n=3)$, poor cooperation $(n=2)$, and refusal $(n=24)$.

Examination of case records showed that the prevalence of diagnosed hay fever or rhinitis and of asthma was slightly higher in the responders (28/366 and 12/366) than in the nonresponders (21/647 and 11/647). This was significant for hay fever and rhinitis $(7 \cdot 6 \%$ : $3.2 \%, \mathrm{p}<0.05)$ but not for asthma $(3 \cdot 3 \%: 1 \cdot 7 \%)$.

\section{RESPONSES TO THE QUESTIONNAIRE}

A positive response was obtained from 32 subjects to the question "Have you at any time suffered from asthma?" (12 with symptoms in the last year), from 81 subjects to the question "Have you at any time suffered from attacks of wheezing of the chest?" from 196 people to the question "Have you at any time had attacks of coughing?" (though only 20 of these subjects said that they had regular attacks of coughing) and from 105 people to the question "Have you

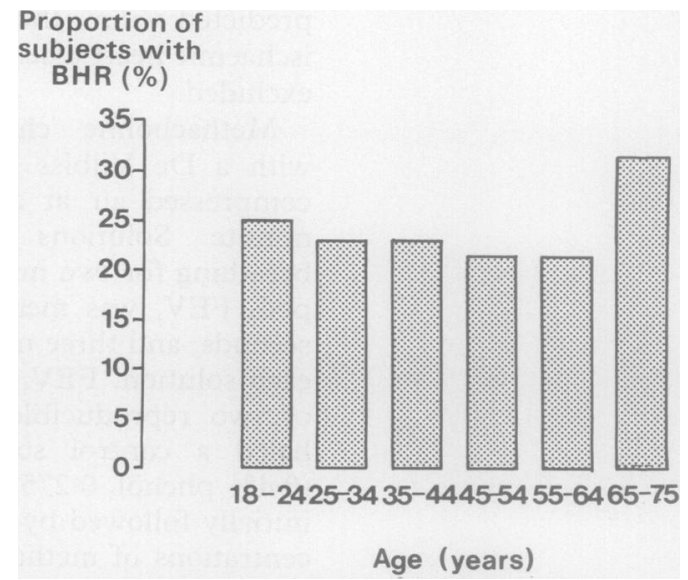

Figure 2 Proportion of subjects showing bronchial hyperresponsiveness (BHR) according to age. 
Table 2 Relation between bronchial hyperresponsiveness (BHR) and asthma, rhinitis, smoking, and atopy: number of individuals with each characteristic, percentage with $B H R$, and significance of relationship ${ }^{\star}$

\begin{tabular}{|c|c|c|c|c|c|c|c|}
\hline & \multicolumn{2}{|c|}{ Current } & \multicolumn{2}{|c|}{ Past } & \multicolumn{2}{|c|}{ Never } & \multirow[b]{2}{*}{ Significance $\left(\chi^{2}\right)$} \\
\hline & No & $\% B H R$ & No & $\% B H R$ & No & $\% B H R$ & \\
\hline \multirow[t]{4}{*}{$\begin{array}{l}\text { Asthma } \\
\text { Rhinitis } \\
\text { Smoking }\end{array}$} & $\begin{array}{l}11 \\
20 \\
96\end{array}$ & $\begin{array}{l}73(n=8) \\
45(n=9) \\
32(n=31)\end{array}$ & $\begin{array}{l}18 \\
64 \\
76\end{array}$ & $\begin{array}{l}33(n=6) \\
25(n=16) \\
21(n=16)\end{array}$ & $\begin{array}{l}280 \\
217 \\
142\end{array}$ & $\begin{array}{l}20(\mathbf{n}=57) \\
22(\mathbf{n}=48) \\
18(\mathbf{n}=25)\end{array}$ & $\begin{array}{l}p<0.01 \\
0.1>p>0.05 \\
p<0.05\end{array}$ \\
\hline & \multicolumn{2}{|c|}{ Atopic } & & & \multicolumn{2}{|c|}{ Non-atopic } & \\
\hline & No & $\% B H R$ & & & No & $\% B H R$ & \\
\hline & 125 & $30(n=38)$ & & & 193 & $17(n=33)$ & $\mathrm{p}<0.01$ \\
\hline
\end{tabular}

*Data not available for asthma for nine patients, for rhinitis for 17 patients, and for smoking for 4 patients.

at any time suffered from attacks of shortness of breath?" (only 15 of whom said that their attacks were regular). Ten people said that they woke at night with attacks of dyspnoea and 10 woke at night with attacks of wheeze. Ninety seven subjects answered "yes" to the question "Have you ever suffered from rhinitis or hay fever?" (20 of whom had had such an attack within the past month).

There were $161(44.5 \%)$ lifelong non-smokers, $105(29 \%)$ current smokers, and 96 $(26.5 \%)$ ex-smokers (that is, they had not smoked any tobacco for at least one month). Fifty one per cent of women and $37 \%$ of men had never smoked.

METHACHOLINE $\mathrm{PC}_{20} \mathrm{FEV}_{1}$ VALUES

Bronchial hyperresponsiveness $\left(\mathrm{PC}_{20} \mathrm{FEV}_{1} \leqslant 2\right.$ $\mathrm{mg} / \mathrm{ml}$ ) was present in 74 subjects $(23 \%$ of those tested). A $20 \%$ fall in $\mathrm{FEV}_{1}$ was seen in 172 subjects (fig 1 ).

\section{SKINPRICK TESTING}

A response to at least one of the common allergens used was seen in 125 people $(39 \%)$, who were therefore regarded as atopic.

RELATION BETWEEN SYMPTOMS, PC $_{20}$ FEV $_{1}$, SEX, AGE, ATOPY, SMOKING, LUNG FUNCTION, AND CUTANEOUS HISTAMINE RESPONSE

Differences in the prevalence of bronchial hyperresponsiveness with age were not statistically significant (fig 2).

Bronchial hyperresponsiveness was more common in women $(31 \%)$ than in men $(13 \%$; p $<0.001)$. Positive responses to the question "Have you ever suffered from attacks of wheezing of the chest?" were, however, almost evenly

Table 3 Binary logistic regression of independent variables on bronchial responsiveness $\left(P C_{20} F E V_{1}\right)$

\begin{tabular}{lllll}
\hline Term entered & $\begin{array}{l}\text { Degrees of } \\
\text { freedom }\end{array}$ & Log likelihood & $\begin{array}{l}\text { Improvement } \\
\left(\chi^{2}\right)\end{array}$ & $p$ \\
\hline Peak flow variability & 1 & $-82 \cdot 820$ & 14.832 & 0.0001 \\
Sex & 1 & -77.391 & 10.859 & 0.001 \\
No of positive skin test & 1 & -71.453 & 11.875 & 0.001 \\
$\quad$ responses & 1 & -67.822 & 7.262 & 0.007 \\
Baseline FEV & 1 & -65.875 & 3.895 & 0.048 \\
Histamine weal area & 1 & & \\
\hline
\end{tabular}

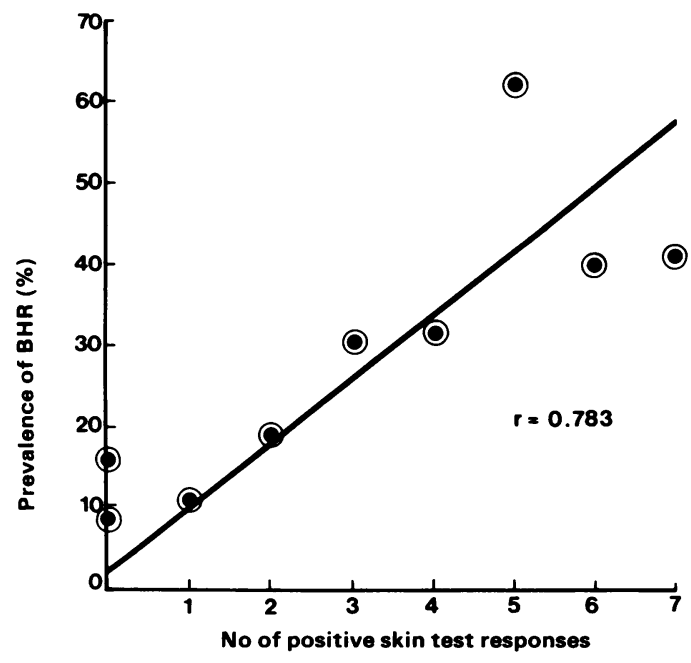

Figure 3 Relation between the number of positive skin test responses and bronchial hyperresponsiveness (BHR).

distributed between the sexes $(31 \%$ of women and $27 \%$ of men). Atopy was slightly more common in men $(43 \%)$ than in women $(35 \%)$.

Bronchial hyperresponsiveness was more common in atopic individuals (30.5\%) than non-atopic individuals $(17 \% ; \mathrm{p}<0.01$-see table 2). There was a positive relation between the presence of bronchial hyperresponsiveness and the number of positive skin test responses $(\mathrm{r}=0.78, \mathrm{p}=<0.05$-see fig 3$)$.

There was a weak but highly significant correlation between $\mathrm{PC}_{20} \mathrm{FEV}_{1}$ and baseline $\mathrm{FEV}_{1}(\mathrm{r}=0.266, \mathrm{p}<0.001)$ and a negative correlation between $\mathrm{PC}_{20} \mathrm{FEV}_{1}$ and mean daily peak flow variability $(\mathrm{r}=-0.241, \mathrm{p}<0.001)$.

Bronchial hyperresponsiveness was more common in subjects who had experienced at least one attack of wheeze $(38 \%)$ than in subjects who had never had wheeze $(18 \%$; p < 0.001 ), but was no more common in subjects who had had attacks of cough or dyspnoea than in those who had not $(23 \% v 24 \%)$. Bronchial hyperresponsiveness was more common in subjects who had had an attack of rhinitis within the last month (table 2) and was present in $48 \%$ of subjects who had ever had an attack of asthma and $73 \%$ of subjects who had had an attack of asthma within the last year (table 2). It was present in $18 \%$ of non-smokers, $21 \%$ of ex-smokers, and $32 \%$ of current smokers ( $p<$ 0.05; table 2).

Stepwise binary logistic regression analysis of independent predictor variables on bronchial hyperresponsiveness showed significant and independent predictive effects for mean daily peak flow variability, sex, the number of positive skinprick test responses, baseline $\mathrm{FEV}_{1}$, and histamine weal area (table 3). There was no significant independent effect for mean allergen weal diameter or for smoking.

RETROSPECTIVE ANALYSIS OF ATTENDANCE WITH RESPIRATORY COMPLAINTS

There was no significant difference in numbers of attendances for upper or lower respiratory complaints between the three groups of patients (fig 4). The subjects' characteristics are shown in table 4 . The ratio of women to 


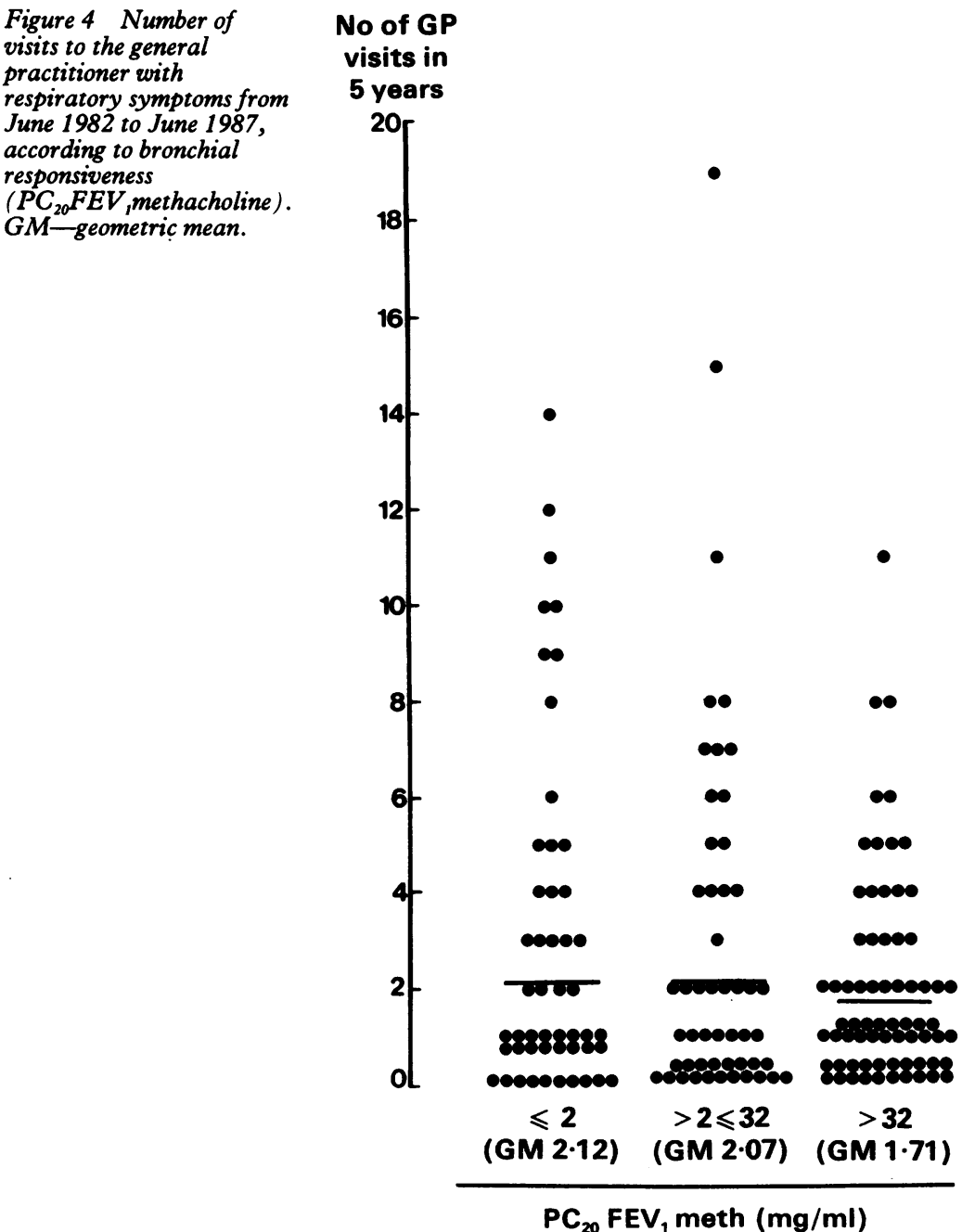

men was $2 \cdot 4: 1$, similar to that of the group with bronchial hyperresponsiveness.

\section{Discussion}

In this study of a systematic 1:12 sample of a general practice population we aimed to recruit a representative sample of the local population to determine the prevalence and associations of bronchial hyperresponsiveness. Several other community studies have been published since this study started. ${ }^{101120-23}$ Our study differs in the technique of recruitment, the availability of information on non-responders, and the area of study.

The sample shows some bias towards recruitment of individuals from the 40-60 year age group, who tend to volunteer more frequently for studies $^{1124}$ (table 1). Using replacements for non-responders has minimised but not eliminated this bias because we could not obtain matched replacements for

Table 4 Subjects' characteristics: analysis of attendances with respiratory complaints: number (\%) with each characteristic for the three groups of $P C_{20} F E V$, range

\begin{tabular}{lllllll}
\hline $\begin{array}{l}P C_{20} F E V, \\
(m g / m l)\end{array}$ & Total & Smoking & Rhinitis & Asthma & $\begin{array}{l}\text { Positive skin } \\
\text { responses }\end{array}$ & $\begin{array}{l}\text { Mean } \\
\text { age }(y)\end{array}$ \\
\hline$\leqslant 2$ & 50 & $20(40)$ & $16(36)$ & $10(20)$ & $26(52)$ & $44 \cdot 0$ \\
$>2, \leqslant 32$ & 51 & $17(34)$ & $10(20)$ & $4(8)$ & $21(41)$ & $46 \cdot 0$ \\
$>32$ & 68 & $13(22)$ & $10(17)$ & 0 & $32(47)$ & $46 \cdot 8$
\end{tabular}

non-responders from the three lists in all cases-for $49 / 415$ of the initial sample $(12 \%)$ no replacement was found. The ratio of men to women (about 3:4), however, reflects that in the practice (2650:3274 in 1984).

Study of case records on non-responders confirmed the tendency for symptomatic individuals to attend for tests. The prevalence of current asthma, however, was similar to that in the practice. During 1984, all attenders at the surgery $(85 \%$ of the practice population attend for some complaint at least once a year) were asked if they had symptoms of asthma in the preceding year as part of a continuous survey ${ }^{27}$ and the prevalence of current asthma was $4.9 \%$ in the age range 18-75, compared with about $4.6 \%(17 / 371)$ in the volunteers (including the five with severe asthma). Although the prevalence among non-responders was lower, the non-responders included multiple replacements for some index individuals and therefore did not represent the practice population. The response rate of $35 \%$ was low but similar to that of other studies. ${ }^{11} 2425$

The prevalence of bronchial hyperresponsiveness was $23 \%$, on the basis of an arbitrary cut off point of a $2 \mathrm{mg} / \mathrm{ml}$ concentration (11 $\mu$ mol cumulative dose) of methacholine. The distribution of bronchial responsiveness appeared to be unimodal in the sample. The highest prevalence recorded in other community surveys of adults was $14 \%$, with a cut off point of $8 \mu \mathrm{mol}$ histamine and the Yan technique. ${ }^{11}$ Aerosol characteristics and deposition vary among the different techniques and some techniques are not directly comparable with others. ${ }^{20-22}$ Studies have shown, however that the $\mathrm{PD}_{20} \mathrm{FEV}_{1}$ (dose delivered to the mouth) is comparable between the method of $\mathrm{Chai}^{28}$ and both the tidal breathing method used in this study $^{29}$ and the Yan technique. ${ }^{30}$ Higher prevalences of bronchial hyperresponsiveness are recorded in children $(23 \%)$ and Australian college students ${ }^{31}(35 \%)$, probably reflecting the age groups studied. The tendency for symptomatic individuals to attend and the practice interest in asthma and atopy may have contributed to the higher prevalence in our sample.

Patients with bronchial hyperresponsiveness might be expected to attend the general practitioner more frequently with respiratory complaints. We were somewhat surprised that this did not appear to be the case, particularly as one fifth of those with bronchial hyperresponsiveness were known to have asthma and the proportions of smokers and of those with rhinitis were also greater in this group. The median attendance of all patients was low, however, with only one to two visits for respiratory complaints in five years, which may reflect a well educated or stoical population who do not attend for minor ailments.

Ten of the 11 subjects with current asthma were women and this may reflect a greater tendency for symptomatic women to attend. Bronchial hyperresponsiveness was more common in women even when those with known asthma were excluded. There was no excess prevalence of wheeze, atopy, or smoking 
among the women and female gender was significantly and independently associated with bronchial hyperresponsiveness according to stepwise binary logistic regression analysis. Thus the sex difference is likely to be real. Other community studies have not found a similar sex difference. ${ }^{101121}$ As there is an excess of women with asthma in this practice the finding may be specific to the local population. Some surveys of asthma have shown an increased prevalence of asthma ${ }^{3233}$ and asthma mortality ${ }^{3435}$ in women.

Eight of the 11 subjects with current asthma had bronchial hyperresponsiveness whereas three did not. A higher cut off point for $\mathrm{PD}_{20} \mathrm{FEV}_{1}$ would include more true positives but also more false positives ${ }^{36}$ given that bronchial responsiveness appears to be unimodally distributed in the population. ${ }^{19-2137}$ Where patients with clearcut asthma are studied the range of values for bronchial hyperresponsiveness clearly differs from that of non-asthmatic subjects. ${ }^{38}$ Subjects with less clearly defined symptoms show a wider range of $\mathrm{PD}_{20} \mathrm{FEV}_{1} \cdot{ }^{37} 39$ Case histories of the three subjects are not available as they have moved from the practice; they may have had less clearly defined symptoms or seasonal asthma, in which levels of bronchial responsiveness are known to fluctuate. ${ }^{40}$

Of the 74 subjects with bronchial hyperresponsiveness, 63 did not admit to having current asthma. There was a strong association between bronchial hyperresponsiveness and the symptom of wheezing, though 33 subjects had never wheezed. Symptoms of cough and dyspnoea were not associated with bronchial hyperresponsiveness and this was not a function of sample size (fig 3). This may be because cough and dyspnoea are less closely associated with airway narrowing. Dyspnoea, however, has been shown to be a predictor for bronchial hyperresponsiveness when the sample is weighted towards a high proportion of symptomatic individuals. ${ }^{24}$

Of those with rhinitis in the preceding month, $45 \%$ had bronchial hyperresponsiveness but only 20 individuals were affected and the association did not reach significance. Allergen exposure is known to increase bronchial responsiveness in sensitised individuals ${ }^{40}$ and this may explain the greater prevalence of bronchial hyperresponsiveness among those with greater numbers of positive skin test responses.

As in other studies, bronchial hyperresponsiveness was more prevalent in smokers and individuals with a low FEV ${ }_{1}{ }^{1011}$ Smoking was not a significant independent predictor for bronchial hyperresponsiveness when stepwise binary logistic regression was carried out, which suggests that the interrelation with low $\mathrm{FEV}_{1}$ was a stronger influence. Because of the relatively few individuals in the older age groups we could not look for the interaction of smoking and age with bronchial responsiveness found by Burney and coworkers. ${ }^{11}$ Peak flow variability was correlated with bronchial responsiveness despite the small numbers with known asthma. The association was indepen- dent of other factors. Peak flow variability appeared to have a continuous distribution similar to that of bronchial hyperresponsiveness, and the degree of variability seen in asthma ${ }^{41}$ is one end of the spectrum.

In summary, the prevalence of bronchial hyperresponsiveness far exceeded that of asthma in this general practice population sample. The phenomenon appeared to be multifactorial in origin with independently significant associations with mean daily peak flow variability, female gender, atopy, resting $\mathrm{FEV}_{1}$, and histamine weal area. Despite the associations with asthma and wheezing, some individuals with bronchial hyperresponsiveness were apparently asymptomatic, and overall attendance at the surgery with respiratory complaints was not significantly increased.

C J $T$ was supported by a grant from the British Lung Foundation. J B B was supported by a grant from the Chest, Heart, and Stroke Association. We are grateful to Laura Roberts for typing the manuscript, Susan Ollier for drawing the diagrams, Janice Thomas for advice on the statistical analysis, and the patients of the Canbury Medical Centre for their time and cooperation.

1 Curry J. The action of histamine on the respiratory tract in normal and asthmatic subjects. $J$ Clin Invest 1946;25: 785-91.

2 Tiffeneau R. Hypersensibilité cholinergo-histaminique pulmonaire de l'asthmatique. Acta Allergol 1958;(suppl 5):187-221

3 Cockcroft DW, Killian DN, Mellon JJA, Hargreave FE Bronchial reactivity to inhaled histamine: a method and clinical survey. Clin Allergy 1977;7:235-43.

4 Boushey HA, Holtzman MJ, Sheller JR, Nadel JA. Bronchial hyperreactivity. Am Rev Respir Dis 1980;121: $389-410$.

5 Stanescu PC, Frans A. Bronchial asthma without increased airway reactivity. Eur $J$ Respir Dis 1982;63:5-12.

6 Ramsdell JW, Nachtwey FJ, Moser KM. Bronchial hyperreactivity in chronic obstructive bronchitis. $\mathrm{Am} \mathrm{Rev}$ Respir Dis 1982;126:829-32.

7 Empey DW, Laitinen LA, Jacobs L, Gold WM, Nadel JA Mechanisms of bronchial hyperreactivity in normal subjects after upper respiratory tract infections. $A m R e v$ Respir Dis 1976;113:131-9.

8 Rhodes BJ, Weiler JM, Donnelly AL, et al. Young asymptomatic non atopic adults have a high prevalence of methacholine airway responsiveness regardless of smoking history [abstract]. Am Rev Respir Dis 1986;133 (part 2): A176.

9 Witt C, Stuckey MS, Woolcock AJ, Dawkins RL. Positive allergy prick tests associated with bronchial histamine responsiveness in an unselected population. J Allergy Clin Immunol 1986;77:698-702.

10 Woolcock AJ, Peat JK, Salome CM, et al. Prevalence of bronchial hyperresponsiveness and asthma in a rural adult population. Thorax 1987;42:361-8.

11 Burney PGJ, Britton JR, Chinn S, et al. Descriptive epidemiology of bronchial reactivity in an adult population: results from a community study. Thorax $1987 ; 42$ 38-44.

12 Cockcroft D, Murdock K, Berscheid B. Relationship between atopy and bronchial responsiveness to histamine in a random population. Ann Allergy 1984;53:26-9.

13 Bryant DH, Burns MW. The relationship between bronchial histamine reactivity and atopic status. Clin Allergy 1976;6:373-81

14 Gerrard JW, Cockcroft DW, Mink JT, Cotton DJ, Poonwala $\mathbf{R}$, Dosman JA. Increased non specific bronchial reactivity in cigarette smokers with normal lung function. Am Rev Respir Dis 1980;122:577-81.

15 Cockcroft DW, Berscheid BA, Murdock KY. Bronchial response to inhaled histamine in asymptomatic young smokers. Eur J Respir Dis 1983;64:207-11.

16 Ryan G, Latimer KM, Dolovich J, Hargreave FE. Bronchial responsiveness to histamine: relationship to diurnal variation of peak flow rate, improvement after bronchodilator, and airway calibre. Thorax 1982;37:432-9.

17 Robinson C, Holgate ST. New perspectives in the putative role of eicosanoids in airway hyperresponsiveness. $J$ Allergy Clin Immunol 1985;76:140-4.

18 Barnes PJ. The third nervous system in the lung: physiology and clinical perspectives [editorial]. Thorax 1984;31 561-7. 
19 Cockcroft DW, Berscheid BA, Murdock KY. Unimodal distribution of bronchial responsiveness in a random human population. Chest 1983;83:751-4.

20 Weiss ST, Tager IB, Weiss JW, et al. Airways responsiveness in a population sample of adults and children. $A m$ Rev Respir Dis 1984;129:898-902.

21 Sears MR, Jones DT, Holdaway MD, et al. Prevalence of bronchial reactivity to inhaled methacholine in New Zealand children. Thorax 1986;41:283-9.

22 Rijcken B, Schouten JP, Weiss ST, Speizer FE, Van der Lende $R$. The relationship of non-specific bronchial hyperresponsiveness to respiratory symptoms in a random population sample. Am Rev Respir Dis 1987;136:62-8.

23 Lee DA, Winslow NR, Speight ANP, Hey EN. Prevalence and spectrum of asthma in childhood. Br Med J 1983, 286:1256-8.

24 Burney PGJ, Chinn S, Britton JR, Tattersfield AE, Papacosta AO. What symptoms predict the bronchial response to histamine? Evaluation in a community survey of the bronchial symptom questionnaire (1984) of the International Union Against Tuberculosis and Lung Disease. Int $J$ Epidermiol 1989;18(1):165-73.

25 Mortagy AK, Howell JBL, Waters WE. Respiratory symptoms and bronchial reactivity: identification of a syndrome and its relation to asthma. Br Med J 1986;293:525-9.

26 Higgins BG, Britton JR, Chinn S, et al. Comparison of histamine and methacholine for use in bronchial challenge tests in community studies. Thorax 1988;43:605-10.

27 Bennett JB, Davies RJ. A comparison of histamine and methacholine challenges using the DeVilbiss 646 nebuliser and the Rosenthal-French dosimeter. $\mathrm{Br} J$ Dis Chest 1987;81:252-9.

28 D'Souza MF. Can I prevent disease and disability? In: Merrell D, ed. Epidemiology in general practice. Oxford: Oxford Medical Publications, 1989:120-2.

29 Chai H, Farr RS, Froelich LA, et al. Standardisation of bronchial challenge procedures. J Allergy Clin Immunol 1975;56:323-7.
30 Yan K, Salome C, Woolcock AJ. Rapid method for measurement of bronchial responsiveness. Thorax 1983; 38:760-5.

31 Cookson WOCM, Musk AW, Ryan G. Association between asthma history, atopy, and non specific bronchial responsiveness in young adults. Clin Allergy 1986;16:425-32.

32 Huhti F. Prevalence of respiratory symptoms, chronic bronchitis and pulmonary emphysema in a Finnish rural population. Acta Tuberc Pneumol Scand 1965;61 (suppl): $1-111$.

33 Juhlin A, Wilhelmsen L. Bronchial asthma and chronic bronchitis in a random population sample. Scand J Respir Dis 1967;48:330-42.

34 Office of Population Censuses and Surveys. Routine mortality statistics: Causes 1978. London: HMSO, 1980.

35 Sly RM. Increase in deaths from asthma. Ann Allergy 1984;53:20-5.

36 Britton J. Is hyperreactivity the same as asthma? Eur Respir J 1988;1:478-9.

37 Rijcken B, Schouten JP, Weiss ST, et al. The distribution of bronchial responsiveness to histamine in symptomatic and asymptomatic subjects. Am Rev Respir Dis 1989;140 615-23.

38 Britton J, Tattersfield AE Does measurement of bronchia hyperreactivity help in the clinical diagnosis of asthma? Eur J Respir Dis 1986;68:233-8.

39 Malo J-L, Pineau L, Cartier A, Martin RR. Reference values of the provocative concentrations of methacholine that cause $6 \%$ and $20 \%$ changes in forced expiratory volume in one section. Am Rev Respir Dis 1983;128:8-11.

40 Boulet L-P Cartier A, Thomson NC, et al. Asthma and increase in non-allergic bronchial responsiveness from seasonal pollen exposure. J Allergy Clin Immunol 1983; 71:399-406.

41 Ryan G, Latimer KM, Dolovich J, Hargreave FE. Bronchial responsiveness to histamine: relationship to diurnal variation of peak flow rate, improvement after bronchodilator and airway calibre. Thorax 1982;37:423-9. 